\title{
Context-Aware Mobile Learning
}

\author{
Anastasios A. Economides \\ ${ }^{1}$ Information Systems Department, University of Macedonia, \\ 156 Egnatia Avenue, Thessaloniki, 54006 GREECE, economid@uom.gr
}

\begin{abstract}
Recent developments on mobile devices and networks enable new opportunities for mobile learning anywhere, anytime. Furthermore, recent advances on adaptive learning establish the foundations for personalized learning adapted to the characteristics of each individual learner. A mobile learner would perform an educational activity using the infrastructure (e.g. handheld devices, networks) in an environment (e.g. outdoors). In order to provide personalization, an adaptation engine adapts the educational activity and the infrastructure according to the context. The context is described by the learner's state, the educational activity's state, the infrastructure's state, and the environment's state. Furthermore, each one of these states is described by its dimensions. Many examples illustrate the adaptation decisions.
\end{abstract}

Keywords: adaptation, adaptive learning, context-aware, knowledge society, learner profile, learner model, mobile learning, personalized learning, pervasive learning, ubiquitous learning.

\section{Introduction}

Recently, there is a widespread use of mobile phones and wireless networks in everyday life. Educational institutes are also starting to exploit mobile devices and networks for learning and management. As most students already possess handheld devices, several educational institutes are using wireless technology to deliver and support mobile learning [1-4]. The intersection of online learning and mobile computing - called mobile learning - holds the promise of offering frequent, integral access to applications that support learning, anywhere, anytime [5]. Mobile learning would help the development of the Knowledge Society. The objective is a society with access to knowledge and learning for everyone [6]. The mobile learner will carry multiple heterogeneous wearable and handheld devices. He will move and interact unrestricted with other learners, hardware and software resources in his neighborhood or on remote locations. He will be able to continually learn wherever he is moving without any mobility, time and other restrictions.

However, the diversity of learners' characteristics as well mobile devices and networks requires personalization for different cases. The educational activities and the provided infrastructure would be auto-configured tailored to the learner needs, interests and abilities. Multiple sources of information would be used to adapt the educational activities and the infrastructure to every situation and condition. Most of the physical objects in the environment will be equipped with some embedded 
sensing and communication capabilities. They will sense, track, and monitor the surrounding environment and transmit this information to those interested for that. This information would be used to make dynamic adaptation decisions for the benefit of the learner.

This paper presents a general framework for context-aware adaptive mobile learning. It explicitly defines the context on which the adaptations would be based. An adaptation engine acquires input data and produces the adaptation results. Part of the input data into the adaptation engine is closely related to the context of ubiquitous computing. This paper defines context to include the learner's state, the educational activity's state, the infrastructure's state, and the environment's state. Several previous studies in ubiquitous computing provided various definitions of context. Location, identity, time and activity have been suggested as primary types of context [7]. Computing context (e.g. network connectivity, communication costs, communication bandwidth, nearby resources such as printers, displays, and workstations), User context (e.g. user's profile, location, people nearby, and current social situation), and Physical context (e.g. lighting, noise levels, traffic conditions, and temperature) have been also proposed as main context categories [8]. In addition to location [9], identities of nearby people and objects, as well as changes to those objects have been included in the context [10]. Context-aware has been defined as "the ability of the computer to sense and act upon information about its environment, such as location, time, temperature or user identity" [11]. Context has been also described across three dimensions: i) Environment (physical and social), ii) Self (device state, physiological and cognitive), and iii) Activity (behavior and task) [12]. Any information that can be used to characterize the situation of an entity (e.g. person, place, or object) would be considered as context [13]. Different types of information about a user can simultaneously be relevant to a given adaptation decision [14]. An ontology-based context model considered time, place, user knowledge, user activity, user environment and device capacity [15]. In parallel, a situation model gave a view on the context model describing temporal properties. It was argued that the following context parameters should be taken into consideration: variety, priority, granularity, implementation, cost-effectiveness [16]. Furthermore, it has been argued that a context aware mobile learning system should also take into consideration the learner's willingness to participate in the proposed learning activity [17].

Several architectures for context-aware applications have been proposed [18-23]. However, implementing such systems on a large scale is not free from obstacles [24]. Educational, socio-cultural, economical, and technical requirements for mobile learning applications should be considered [25]. A mechanism to support adaptation in m-learning systems has been proposed [26]. An ontology-based framework for context-aware mobile learning has been proposed [27]. Context-aware social presence mechanisms would support a learner [28]. Instant messaging would provide the learner with continuous access to social networks. A three-tier web-based architecture has been proposed for context-aware m-learning [29]. Similarly, "SmartContext" was an ontology based context model which included a standardized context template, a context reasoning ontology and a context middleware [30]. A flexible e-learning model would take into consideration the learner's knowledge state and learning preferences [31] to create personalized learning paths [32]. Furthermore, the users 
may prefer informal communication and learning [33]. The architecture of a contextaware schedule tool for learning Java has been proposed in [34]. A context-aware system consisting of three components has been proposed [35]. Also, the user's vision and speech would be monitored [36].

In this paper, an adaptation engine adapts the learner's educational activity or/and infrastructure according to the context. The adaptation decisions would be either deterministic or probabilistic [37]. The next section 2 presents the context on which the adaptations would be based.

\section{Context model}

The context is defined to consist of the learner's state, the educational activity's state, the infrastructure's state, and the environment's state. Next, each one of these states is further described by its dimensions. Each dimension would be further analyzed to its variables. It is obvious that the more information is available about each dimension, the more accurate but complicated the model becomes. The proper type and number of dimensions remains an open research issue. Adding additional dimensions will increase the complexity of the model and the requirements to collect additional information. There may be a balance between the number of dimensions, model complexity, and the accuracy of the model. Techniques for modifying the weights associated with different dimensions dynamically to better represent the context are open research issues. The same stands for the variables in each dimension.

\section{1. Learner's state}

The Learner's state is described by the following dimensions (with examples):

Demographics, e.g. the educational activity should be adapted to a learner who has grown up in a loose time orientation culture. In this case the learner may not be punctual with deadlines and scheduling, and therefore the educational activity should adapt to afford loose deadlines.

Education \& Profession, e.g. if the learner has practicing experiences, then the educational activity should be adapted to provide him with pragmatic cases, real life projects, and experiments.

Preferences \& Interests, e.g. if the learner prefers audio communication, then the educational activity and the infrastructure should be adapted to increase the audio communication (e.g. speak the instructions).

Objectives, Aims \& Plans, e.g. the educational activity should be adjusted to the short and long term objectives of the learner.

Health, e.g. if the learner is overweight, then the educational activity and the infrastructure should be adapted to his weight.

Physical Abilities, e.g. if the learner has movement disability, then the educational activity should be adjusted to take place in a given space.

Cognitive Abilities, e.g. if the learner learns inductively, then the educational activity should proceed step-by-step in an inductive way. 
Social Abilities, e.g. if the learner has leadership abilities, then the educational activity may assign him the coordinator's role in a group task.

Feelings \& Emotions, e.g. if the learner is bored, then the educational activity may become more intriguing.

Intentions, Wills \& Values, e.g. if the learner underestimates his abilities, then the educational activity may tailor the project to his performance level, in order that he becomes motivated and successful.

Time \& Schedule, e.g. if the learner is required to complete a project in a given deadline, the educational activity may remind him some time in advance as well as alert him on the deadline.

Location, e.g. If the learner approaches a specific object, then the educational activity may give him further instructions and directions.

Mobility, e.g. the educational activity may guide and teach the learner through a botanical garden.

Current Needs \& Desires, e.g. if the learner is thirsty, then the educational activity may suggest him of drinking locations.

Wearable \& handheld hardware, software and other resources, e.g. if the screen of the learner's handheld device is small, then the educational activity may be adapted to show the summary and the main points instead of the full content.

Tasks, Results \& Achievements, e.g. if the learner is performing excellent, then the educational activity may increase the difficulty level.

Restrictions, e.g. if there are access restrictions to some resources for the learner, then the educational activity should consider these.

\section{2 Educational Activity's state}

The Educational Activity's state is described by the following dimensions (with examples):

Subject, e.g. if the subject of the educational activity is related to drawing, then wizards and auto-shapes facilities may be activated.

Requirements, e.g. if the educational activity requires video delivery, then the infrastructure should adapt to reserve high bandwidth and storage capacity.

Purpose, if the educational activity purpose is to assess the learner's knowledge, then a test may be taken by her.

Expected Outcomes, e.g. if the educational activity outcome is to increase the learner's synthesis ability, then it may ask the learner to assemble parts into an integrated system.

Pedagogical Theory, e.g. if the teacher wants the educational activity to be based on collaboration, then the educational activity may set up learner teams and ask them to complete a collaborative project.

Management, e.g. if the educational activity is coordinated by an examiner, then its tasks may have strict deadlines and access restrictions may be imposed too.

Content, e.g. if the learner is an activist type, then the educational activity may be tailored around real cases and experiments. 
Presentation, e.g. if the learner is a visual type, then more visual than audio objects may be presented to her.

Structure \& Sequencing, e.g. if the learner is a sequential learner, then the educational content may be presented inductively and step by step.

Resources, e.g. if the educational activity helps the learner, then it may provide to him further bibliography and links on the Web.

Participants \& Teams, e.g. if the educational activity establishes teams, then the infrastructure should try to keep on connectivity among the team members during the whole activity duration.

Achievements \& Results, e.g. if the educational activity records the learner's progress, then it may become easier or harder depending on the learner's achievements.

\subsection{Infrastructure's state}

The Infrastructure's state is described by the following dimensions (with examples): Devices, e.g. if the learner walks on a mountain, then adjustment of the antenna range or/and the communication technology may be needed.

Networks, e.g. if the communication jitter is high and the quality of video transmission is low, then alternative communication channels or alternative media should be selected.

Hardware and Software Resources, e.g. if the learner is close to an energy charger and his battery lifetime is short, then the system may notify him about the available charger.

Adaptable Activities, e.g. if there is interference with other adaptable activities in the vicinity of the learner, adjustments on the antenna range or the communication protocols may be done.

\subsection{Environment's state}

Finally, the Environment's state is described by the following dimensions (with examples):

Terrain, e.g. if the learner moves from outdoors to indoors, then a different network technology may be selected.

Weather, e.g. if there is a lot of sunlight, then the screen should be adjusted to not reflect the light.

Environmental Characteristics, e.g. if there is a lot of noise in the environment, then the audio volume may be increased or text communication may be enabled.

Neighbors, e.g. if there are available neighbors, then the network can use them as intermediate nodes in order to connect two communicating faraway learners.

Non-adaptable Activities, e.g. if other non-adaptable activities are running, then they should be considered in the battery consumption. 


\section{Conclusions}

The paper presents a general framework for context-aware adaptive mobile learning. The mobile learner learns and performs an educational activity as he moves in an environment. The goal is to help the mobile learner, to increase his satisfaction and learning, to decrease his limitations and restrictions in order to be unconcernedly engaged in learning. The learner is supported by an adaptation engine that adapts the educational activity and/or the infrastructure according to the context. This paper explicitly defines the context to consist of the learner's state, the educational activity's state, the infrastructure's state, and the environment's state.

The presented framework may help designers and developers of mobile learning systems at their decisions. It may help them to identify requirements, open problems, challenges and opportunities, to share ideas and methods, to take a holistic approach in developing systems and thoroughly evaluate them. In order to expand students' and citizens' opportunities, government would consider adopting lifelong mobile learning into the educational system. People would learn not only in formal situations (e.g. in class) but everywhere (e.g. while working, collaborating, walking, playing) anytime.

Hopefully, this study would stimulate future research and development efforts. An initial step would be the implementation of a simple case. The adaptation engine would accept as input the learner's location and would select the team members in an outdoors collaborative activity $[38,39]$. The ultimate goal will be the implementation of adaptation engines that use the full context and produce the full adapted educational activity and infrastructure, as presented in the Context model section. Another idea for future work would be the harmonious integration of the input data, as well as the explicit decisions under various input data combinations.

\section{References}

1. Davis, S: Observations in classrooms using a network of handheld devices. Journal of Computer Assisted Learning 19 (2003), pp. 298-307.

2. Waycott, J. \& Kukulska-Hulme, A.: Students' experience with PDAs for reading course materials. Personal and Ubiquitous Computing 7 (2003), pp. 30-43.

3. Sung, M., Gips, J., Eagle, N., Madan, A., Caneel, R., Devaul, R., Bonsen, J. \& Pentland, A.: Mobile-IT education (mit.edu): m-learning applications for classroom settings. Journal of Computer Assisted Learning 21 (2005), pp. 229-237.

4. Economides, A.A. and Nikolaou, N.: Evaluation of handheld devices for mobile learning. International Journal of Engineering Education (IJEE) 24(1), January 2008, pp. 3-13.

5. Tatar, D., Roschelle, J., Vahey, P. \& Penuel, W.R.: Handhelds go to school: Lessons learned. IEEE Computer 36(9), September 2003, pp. 30-37.

6. Lytras, M.D. \& Sicilia, M.A.: The knowledge society: A manifesto for knowledge and learning. International Journal of Knowledge and Learning 1 (1/2), 2005, pp. 1-11.

7. Schilit, B.N., Theimer, M.M. \& Welch, B.B.: Customizing mobile applications. In: Proceedings of the USENIX Symposium on Mobile and Location-Independent Computing, (USENIX Association), August 1993, pp. 129-138.

8. Schilit, B., Adams, N. \& Want, R.: Context-aware computing applications. In: Proceedings of IEEE Workshop on Mobile Computing Systems and Applications, pp. 85-90, Santa Cruz, California, December 1994. IEEE Computer Society Press (1994). 
9. Becker, C. \& Durr, F.: On location models for ubiquitous computing. Personal Ubiquitous Computing 9 (2005), pp. 20-31.

10. Schilit, B.N. \& Theimer, M.M. Disseminating active map information to mobile hosts. IEEE Networks, 8(5), 1994, pp. 22-32.

11. Ryan, N., Pascoe, J. \& Morse, D.: Enhanced reality fieldwork: the context-aware archaeological assistant. In: Computer Applications in Archaeology 1997, British Archaeological Reports, Oxford, October 1998.

12. Schmidt, A., Beigl, M. \& Gellersen, H.W.: There is more to context than location. Computers and Graphics Journal 23(6), 1999, pp. 893-902.

13. Dey, A.K. \& Abowd, G.: Towards a Better Understanding of Context and ContextAwareness. In: 2000 Conference on Human Factors in Computing Systems (CHI 2000), The Hague, The Netherlands, April 3, 2000.

14. Tamminen, S., Oulasvirta, Toiskallio, K. \& Kankaninen, A.: Understanding mobile contexts. Personal and Ubiquitous Computing 8 (2004), pp. 135-143.

15. Bouzeghoub, A., Do, K.N. and Lecocq, C.: A situation-based delivery of learning resources in pervasive learning. In: E.Duval, R. Klamma, and M. Wolpers (Eds.): EC-TEL 2007, LNCS 4573, pp. 450-456. Springer-Verlag Berlin Heidelberg (2007).

16. Fatma Bayoumi: Context aware systems: Present and Future. In: Proceedings of the IASTED European Conference, Internet and Multimedia Systems and Applications, Chamonix, France, pp. 208-213, 2007.

17. Uday Bhaskar, N. and and Govindarajulu, P.: A design methodology for acceptability analyzer in context aware adaptive mobile learning systems development. In: IJCSNS International Journal of Computer Science and Network Security 8(3), 2008, pp. 130-138.

18. Dey, A.K.: Understanding and using context. Personal and Ubiquitous Computing 5 (2001), pp. 4-7.

19. Jameson, A.: Modelling both the context and the user. Personal and Ubiquitous Computing 5 (2001), pp. 29-33.

20. Petrelli, D., Not, E., Zancanaro, M., Strapparava, C. \& Stock, O.: Modelling and adapting to context. Personal and Ubiquitous Computing 5 (2001), pp. 20-24.

21. Indulska, J. \& Sutton, P.: Location management in pervasive systems. In: Johnson, C. Montague, P. \& Steketee, C. (Eds.), Workshop on Wearable, Invisible, Context-Aware, Ambient, Pervasive and Ubiquitous Computing, Conferences in Research and practice in Information Technology, Vol. 21 (2003), Australian Computer Society.

22. Lonsdale, P., Baber, C., Sharples, M. \& Arvanitis, T.N.: A context awareness architecture for facilitating mobile learning. In: Proceedings MLEARN 2003.

23. Biegel, G. \& Cahill, V.: A framework for developing mobile, context-aware applications. In: Proceedings of the Second IEEE Annual Conference on Pervasive Computing and Communications (PERCOM'04), IEEE 2004.

24. Raisinghani et al.: Ambient intelligence: changing forms of human-computer interaction and their social implications. Journal of Digital Information 5(4), Article No. 271, 2004.

25. Economides, A.A.: Requirements of mobile learning applications. International Journal of Innovation and Learning 5(5), 2008, pp. 457-479.

26. Martin, E., Carro, R.M. and Rodriguez, P.: A mechanism to support context-based adaptation in m-learning. In: W. Neijdl and K. Tuchtermann (Eds.): EC-TEL 2006, LNCS 4227, pp. 302-315, Springer-Verlag Berling Heidelberg (2006).

27. Berri, J., Benlamri, R. and Atif, Y.: Ontology-based framework for context-aware mobile learningh. In: IWCMC'06, July 2006, Vancouver, British Columbia, pp. 1307-1310. Canada, ACM 2006.

28. Kekwaletswe, R.M. and Ng'ambi, D.: Ubiquitous social presence: Context-awareness in a mobile learning environment. In: Proceedings of the IEEE International Conference on Sensor Networks, Ubiquitous, and Trustworthy Computing (SUTC'06), pp. 1-6, IEEE 2006. 
29. Basaeed, E.I., Berri, J., Zemerly, M.J. and Benlamri, R.: Web-based context-aware mlearning architectyre. International Journal Interactive Mobile Technologies 1(1), October 2007, pp. 5-10.

30. Hu, B. and Moore, P.: "SmartContext": An ontology based context model for cooperative mobile learning. In: W. Shen et al. (Eds.): CSCWD 2006, LNCS 4402, pp. 717-726. Springer-Verlag Berlin Heidelberg (2007).

31. Albano, G., Gaeta, G. \& Salerno, S.: E-learning: A model and process proposal. International Journal of Knowledge and Learning 2 (1/2), 2006, pp. 73-88.

32. Albano, G., Gaeta, G. \& Salerno, S.: IWT: An innovative solution for AGS e-learning model. International Journal of Knowledge and Learning 3 (2/3), 2007, pp. 209-224.

33. Groth, K., Bogdan, C., Lindqvist, S. \& Sundblad, Y.: Simple and playful interaction for informal communication and learning. International Journal of Knowledge and Learning 3 (2/3), 2007, pp. 191-208.

34. Yau, J. and Joy, M.: Architecture of a context-aware and adaptive learning schedule for learning Java. In: Seventh IEEE International Conference on Advanced Learning Technologies (ICALT 2007), pp. 1-5, IEEE 2007.

35. Yau, J. and Joy, M.: A context-aware and adaptive learning schedule framework for supporting learners' daily routines. In: Second International Conference on Systems (ICONS'07), pp. 1-6, IEEE 2007.

36. Porta, M.: E-learning and machine perception: In pursuit of human-line interaction in computer-based teaching systems. International Journal of Knowledge and Learning 3 (2/3), 2007, pp. 281-298.

37. Economides, A.A.: Adaptive mobile learning. In: Proceedings IEEE WMUTE- 4th International Workshop on Wireless, Mobile and Ubiquitous Technologies in Education (2006), Athens, Greece, November 2006, pp. 26-28, IEEE 2006.

39. Vasiliou, A. and Economides, A.A.: MANET-based outdoor collaborative learning. In: Proceedings 3rd International Conference on Interactive Mobile and Computer Aided Learning (IMCL 2008), Amman, Jordan.

40. Vasiliou, A. and Economides, A.A.: Mobile collaborative learning using multicast MANETs. International Journal of Mobile Communications (IJMC) 5(4), 2007, pp. 423444. 